\title{
Prolonged wakefulness induces experience- dependent synaptic plasticity in mouse hypocretin/orexin neurons
}

\author{
Yan Rao, ${ }^{1}$ Zhong-Wu Liu, ${ }^{1,2}$ Erzsebet Borok, ${ }^{1}$ Rebecca L. Rabenstein, ${ }^{3}$ Marya Shanabrough, ${ }^{1}$ \\ Min Lu, ${ }^{1}$ Marina R. Picciotto,,3,4 Tamas L. Horvath,1,4,5 and Xiao-Bing Gao'1

\begin{abstract}
1Department of Obstetrics, Gynecology and Reproductive Sciences, Yale University School of Medicine, New Haven, Connecticut, USA.
2Department of Neurobiology, Yunyang Medical College, Shiyan, Hubei, People's Republic of China. ${ }^{3}$ Department of Psychiatry,
\end{abstract} \\ ${ }^{4}$ Department of Neurobiology, and ${ }^{5}$ Section of Comparative Medicine, Yale University School of Medicine, New Haven, Connecticut, USA.
}

\begin{abstract}
Sleep is a natural process that preserves energy, facilitates development, and restores the nervous system in higher animals. Sleep loss resulting from physiological and pathological conditions exerts tremendous pressure on neuronal circuitry responsible for sleep-wake regulation. It is not yet clear how acute and chronic sleep loss modify neuronal activities and lead to adaptive changes in animals. Here, we show that acute and chronic prolonged wakefulness in mice induced by modafinil treatment produced long-term potentiation (LTP) of glutamatergic synapses on hypocretin/orexin neurons in the lateral hypothalamus, a well-established arousal/ wake-promoting center. A similar potentiation of synaptic strength at glutamatergic synapses on hypocretin/orexin neurons was also seen when mice were sleep deprived for 4 hours by gentle handling. Blockade of dopamine D1 receptors attenuated prolonged wakefulness and synaptic plasticity in these neurons, suggesting that modafinil functions through activation of the dopamine system. Also, activation of the cAMP pathway was not able to further induce LTP at glutamatergic synapses in brain slices from mice treated with modafinil. These results indicate that synaptic plasticity due to prolonged wakefulness occurs in circuits responsible for arousal and may contribute to changes in the brain and body of animals experiencing sleep loss.
\end{abstract}

\section{Introduction}

Sleep is a natural process that allows mammals to preserve energy; it facilitates development, and results in recuperation of the nervous system $(1,2)$. It is still unclear how the central nervous system responds to the increasing pressure resulting from the demand to keep awake during compulsory or voluntary sleep loss. Neuronal changes are likely to be important for overcoming the transition from the waking state to sleep but are also likely to contribute to the well-documented effects of sleep loss on the mammalian brain (3-5). It is clear that the activity of particular groups of neurons in wake-promoting centers increases during normal waking states as well as during sleep deprivation (SD), as demonstrated by increased spike firing, expression of c-Fos, and expression of a large spectrum of genes in these neurons (6-9); however, the fundamental question of how the demand for staying awake is translated into the increased activity and gene expression in these wake-promoting neurons remains unanswered.

Among the brain regions orchestrating the regulation of the sleep-wake cycle, the lateral hypothalamus ( $\mathrm{LH}$ ) has long been suggested to be a center responsible for arousal and maintenance of wakefulness (10). It is clear that a specific group of neurons expressing the neuropeptide hypocretin (also called orexin) in the LH promote wakefulness (11-13). Anatomically, hypocre-

Nonstandard abbreviations used: AMPA, $\alpha$-amino-3-hydroxy-5-methylisoxazole4-propionic acid; AMPAR, AMPA receptor; AP5, DL-2-amino-5-phosphonovaleric acid; DA, dopaminergic; EPSC, excitatory postsynaptic current; For-LTP, forskolininduced LTP; LH, lateral hypothalamus; LTP, long-term potentiation; mEPSC, miniature excitatory postsynaptic current; NMDAR, NMDA receptor; SD, sleep deprivation/sleep deprived.

Conflict of interest: The authors have declared that no conflict of interest exists. Citation for this article: J. Clin. Invest. 117:4022-4033 (2007). doi:10.1172/JCI32829. tin/orexin-expressing neurons receive and integrate inputs from many brain areas and send nerve fibers to major arousal centers in the brain $(13,14)$. The concentration of hypocretin/orexin in the cerebrospinal fluid and the action potential firing in hypocretin/ orexin neurons fluctuate with the behavioral state of animals during the day (15-20). Consistent with its role in promoting alertness and arousal/wakefulness, the hypocretin/orexin system has been demonstrated to be highly plastic and easily activated upon challenge with stressors $(21,22)$. There is also recent evidence that hypocretin/orexin neurons are required for wakefulness and attention during SD (9); however, the adaptive changes underlying the ability of hypocretin/orexin neurons to drive prolonged wakefulness and respond to the increased demands for arousal have not been elucidated.

It is clear that excitatory synapses undergo long-term potentiation (LTP) as a result of coordinated activation. In addition, LTP appears to be a ubiquitous mechanism through which the brain makes adaptive changes in neuronal circuitry in response to demands from the external environment (23), such as learning a new skill (24) or adapting to a behavioral change (25). In this study we demonstrate that experience-dependent long-term plasticity takes place at glutamatergic synapses on hypocretin/orexin neurons during prolonged exposure to wakefulness in animals, consistent with the fact that glutamatergic synaptic transmission on hypocretin/orexin neurons provides a major excitatory input to these neurons and is essential to the functioning of the hypocretin/orexin system $(22,26,27)$. Our data indicate that prolonged exposure to wakefulness leads to experience-dependent synaptic plasticity, including LTP at synapses on arousal/wakefulness-promoting neurons, which are required to keep functioning in order to maintain sufficient alert and wakefulness during long-term sleep loss. 

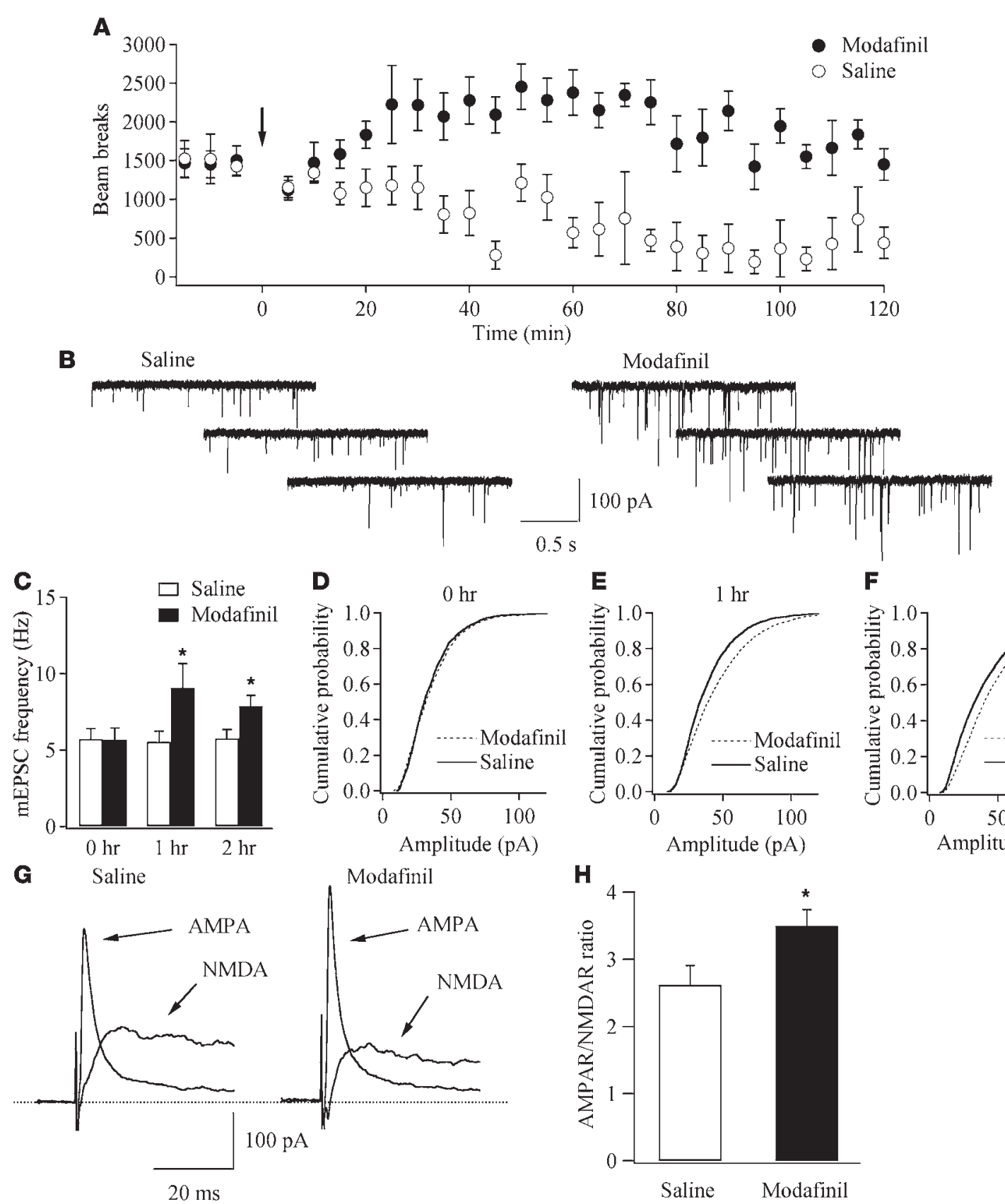
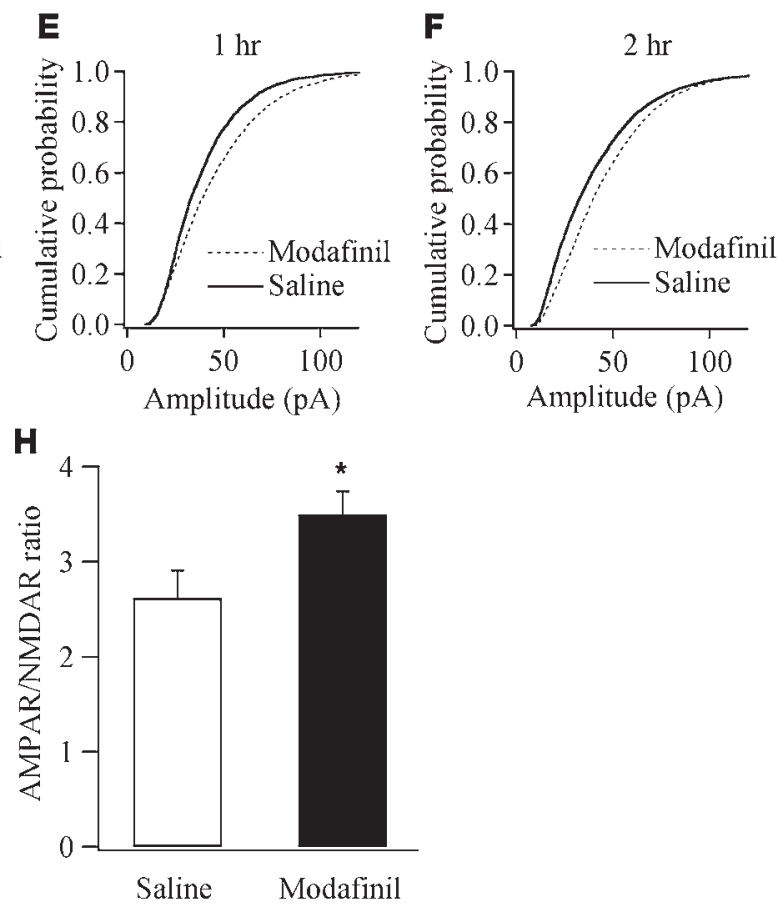

\section{Figure 1}

LTP of excitatory synapses on hypocretin/orexin neurons following an acute exposure to prolonged wakefulness. (A) Modafinil (100 mg/kg) induces a long-lasting increment of locomotor activity in mice. Each point represents averaged beam breaks within a block of 5 minutes from all animals in each group during our experiments. The arrow indicates injection of modafinil or saline. (B) Sample traces of mEPSCs recorded in hypocretin/orexin neurons from saline- and modafinil-treated mice. (C) Mean frequency of mEPSCs recorded in hypocretin/orexin neurons 0 , 1, and 2 hours after the injection of saline or modafinil. ${ }^{*} P<0.05$, Student's $t$ test. (D-F) Cumulative probability of the amplitude of mEPSCs recorded in all neurons from saline- and modafinil-treated mice 0, 1, and 2 hours after the injection. (D) Saline, 1,518 events; modafinil, 1,557 events. (E) Saline, 4,510 events; modafinil, 2,753 events. (F) Saline, 3,250 events; modafinil, 3,942 events. ( $\mathbf{G}$ and $\mathbf{H}$ ) Relative contributions of AMPARs and NMDARs on evoked EPSCs recorded in hypocretin/orexin neurons from mice treated with saline and modafinil. (G) Sample traces of evoked EPSCs carried by AMPARs and NMDARs in hypocretin/orexin neurons from mice treated with saline (left) and modafinil (right). (H) Pooled data of the AMPAR/NMDAR ratio from all neurons in saline- $(n=10)$ or modafinil-treated mice $(n=10) 1$ hour after the injection. ${ }^{*} P<0.05$, Student's $t$ test.

\section{Results}

Prolonged wakefulness induces experience-dependent plasticity in bypocretin/orexin neurons. Modafinil (diphenylmethyl-sulfonyl-2-acetamide) is approved by the FDA for the treatment of narcolepsy and many other conditions $(28,29)$. Modafinil significantly enhances vigilance, alertness, and wakefulness in patients, with limited potential for addiction and without anxiogenic effects (28-30). The enhancement of wakefulness by modafinil occurs at the 
A

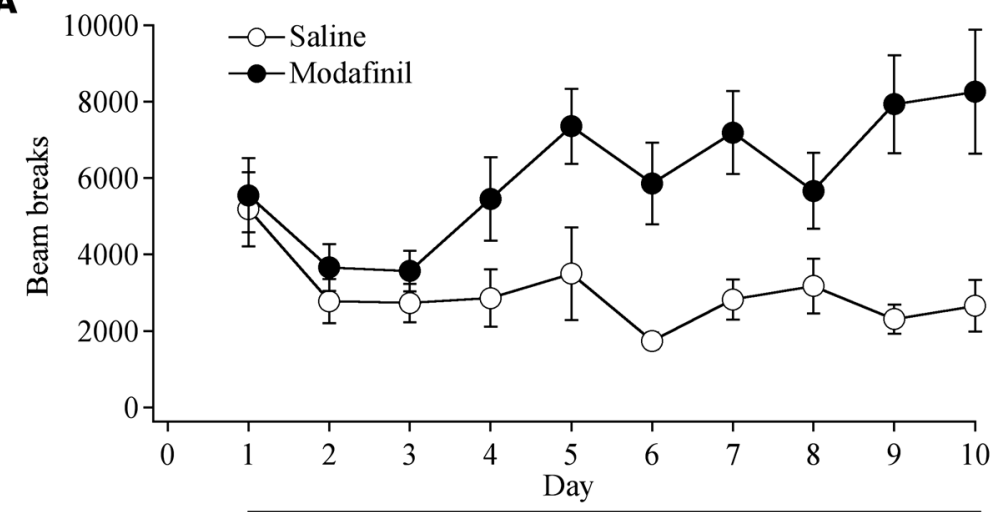

B

\begin{tabular}{|l|l}
\hline habituation & treatment \\
\hline
\end{tabular}

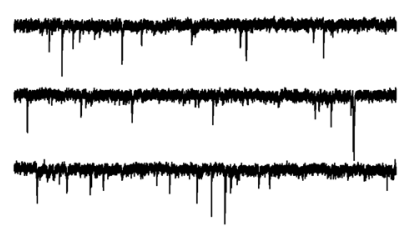

C

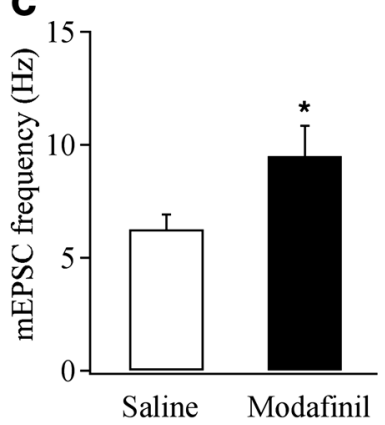

D

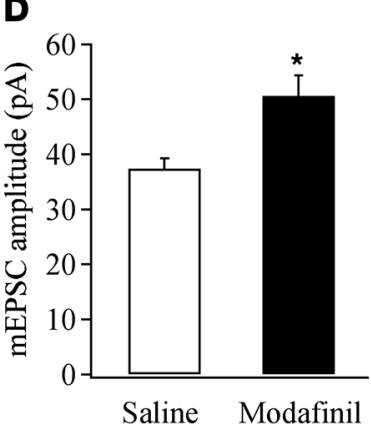

$\mathbf{F}$
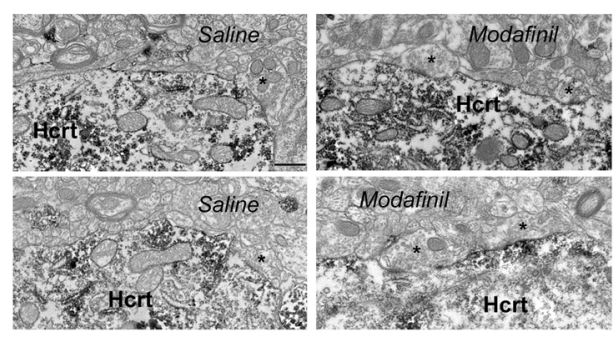

Modafinil

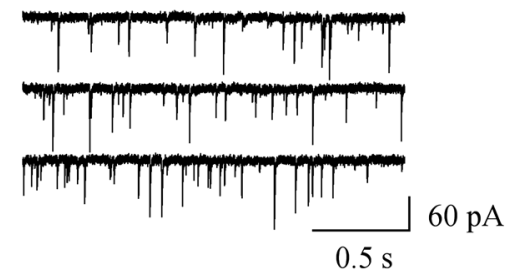

E

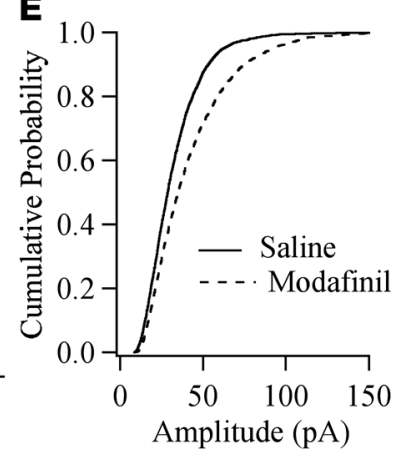

G

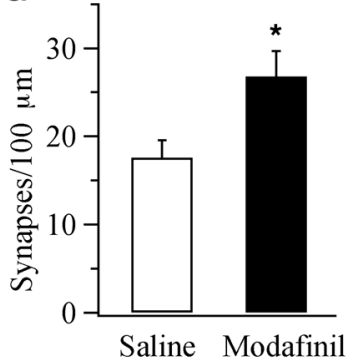

Figure 2

Experience-dependent synaptic plasticity in mice chronically exposed to prolonged wakefulness. (A) Measurement of locomotor activity indicates development of behavioral sensitization in mice chronically treated with modafinil. Each point represents averaged beam breaks in a 30-minute session from all mice in each group. (B) Sample traces of mEPSCs recorded in hypocretin/orexin neurons from mice chronically treated with saline or modafinil 1 day after the completion of the 7-day treatment. (C) Pooled data from all recorded neurons in control mice and mice chronically exposed to prolonged wakefulness indicate the potentiated frequency of mEPSCs in modafinil-treated mice. ${ }^{*} P<0.05$, Student's $t$ test. (D) Pooled data from all recorded neurons in control mice and mice chronically exposed to wakefulness indicate the potentiated amplitude of mEPSCs in modafinil-treated mice. ${ }^{*} P<0.05$, Student's $t$ test. (E) Cumulative probability of the amplitude of mEPSCs recorded from mice treated with modafinil $(4,163$ events) or saline $(3,232$ events). The rightward shift of cumulative distribution of mEPSC amplitude in the modafiniltreated group was significant $(P<0.001$, Kolmogorov-Smirnov test). ( $\mathbf{F}$ and $\mathbf{G})$ Chronic treatment with modafinil increases the number of asymmetric (putative excitatory) synapses on perikarya containing hypocretin/orexin (Hcrt). (F) Electron micrographs of asymmetric (putative excitatory) synapses on hypocretin/orexin-containing perikarya in saline- (left) or modafinil-treated mice (right). Presynaptic terminals are indicated by the asterisk. Scale bar: $1 \mu \mathrm{m}$. (G) Bar graph shows the numbers of asymmetric synapses per $100 \mu \mathrm{m}$ perikaryal membrane of hypocretin neurons in saline- or modafinil- treated mice. ${ }^{*} P<0.05$. expense of slow-wave and paradoxical sleep, probably as a result of increasing the dopaminergic (DA) tone through the blockade of the dopamine transporter $(31,32)$.

In the current study, male C57BL/ 6 mice were administered modafinil $(100 \mathrm{mg} / \mathrm{kg}$, i.p.) or saline, and locomotor activity (saline: $n=5$, modafinil: $n=5$ ) was measured during the light portion of the light-dark cycle as an indicator of wakefulness. Treatment of mice with modafinil induced a significant increase in locomotor activity lasting for 2 hours (Figure 1A), as demonstrated by a significant effect of treatment $\left(F_{1,26}=3.024 ; P<0.01\right.$, repeated measures ANOVA). The absence of sleep in modafiniltreated compared with saline-treated mice throughout the exper- iments was confirmed by visual observation. Saline-treated mice spent a considerable amount of time sleeping in the testing cages, resulting in a significant decline in beam breaks throughout the experiment. In accord with previous results reported by Edgar and Seidel demonstrating that modafinil increased wake time but did not increase locomotor activity above the level expected for normal waking animals (33), the results reported here show that acute exposure to modafinil can induce long-lasting wakefulness in mice, as has been shown in rats and hamsters $(32,33)$. The acute effect of modafinil is reversible, since the locomotor activity of modafinil-treated mice returned to baseline levels the next day (data not shown). 
A
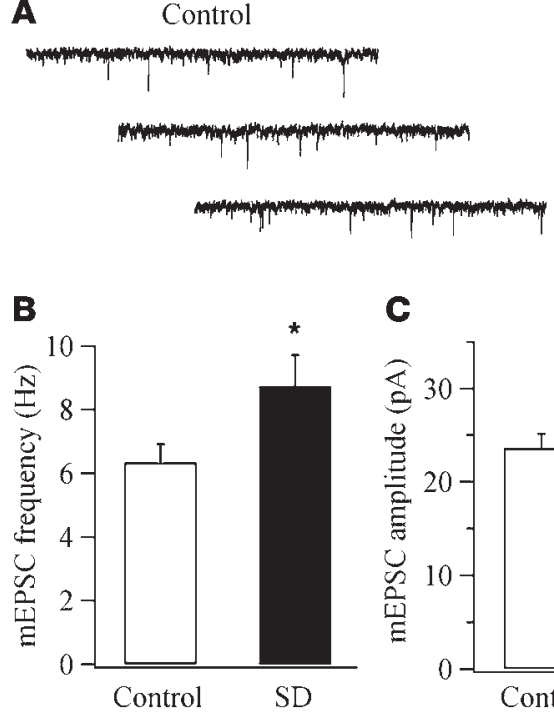

c
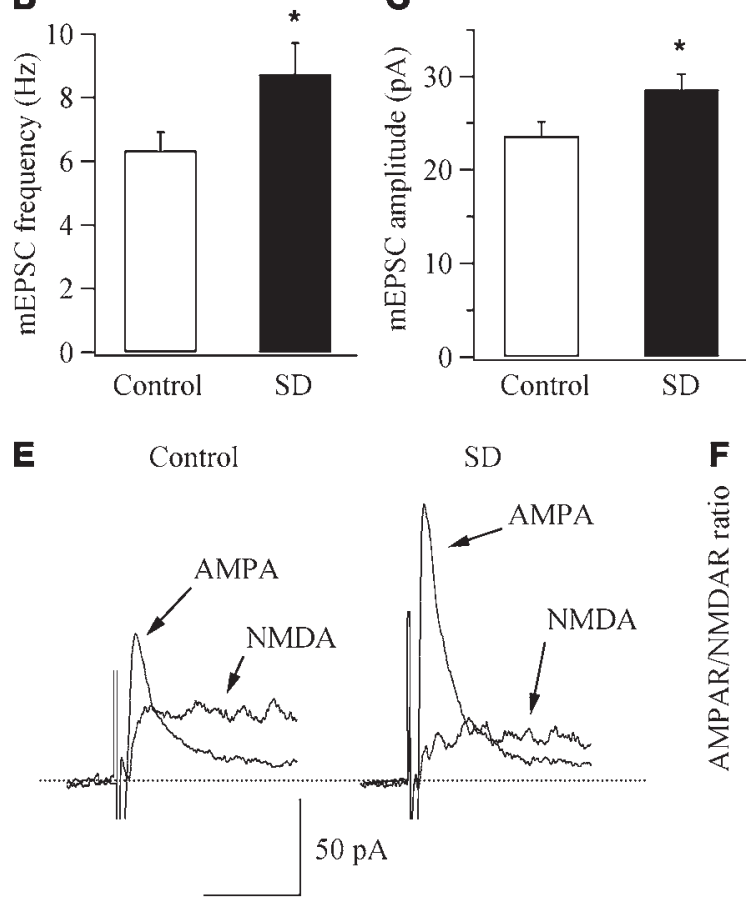

$10 \mathrm{~ms}$

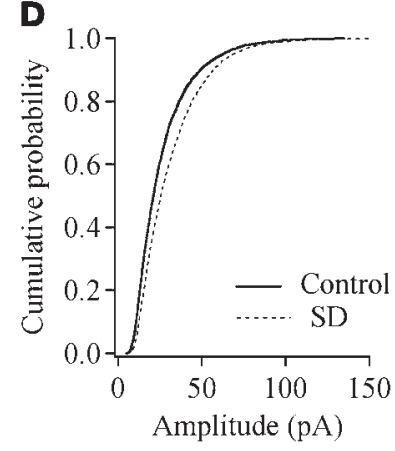

$\mathrm{SD}$
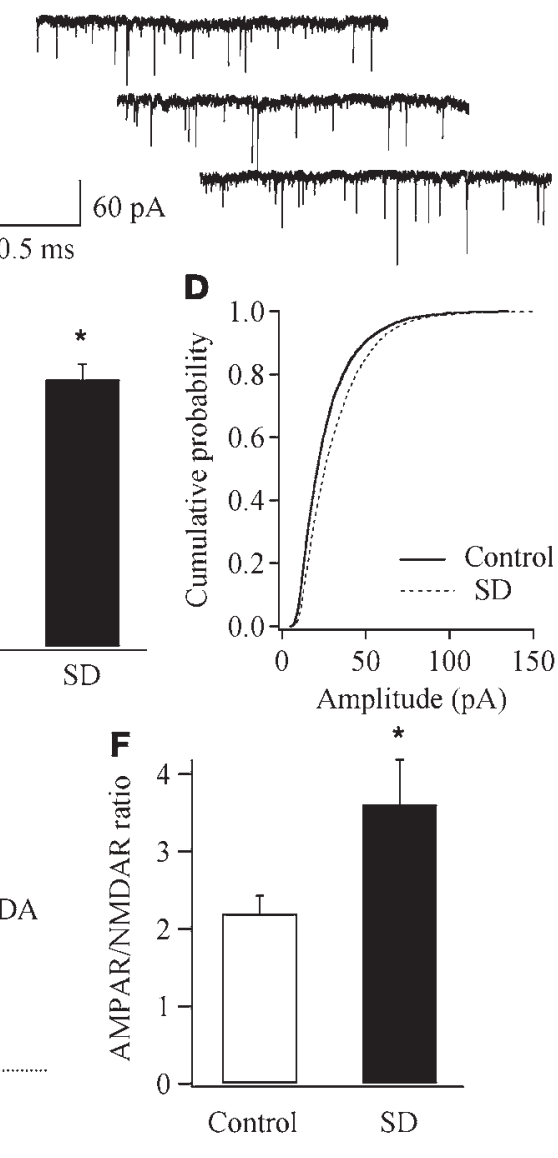

Figure 3

LTP of excitatory synapses on hypocretin/ orexin neurons following SD. (A) Sample traces of mEPSCs recorded in hypocretin/orexin neurons from control and SD mice. SD mice were deprived of sleep for 4 hours through gentle handling. (B) The mean frequency of mEPSCs recorded in hypocretin/orexin neurons from control and SD mice. ${ }^{\star} P<0.05$, Student's $t$ test. (C) The mean amplitude of mEPSC events recorded in hypocretin/orexin neurons from control and SD mice. ${ }^{*} P<0.05$, Student's $t$ test. (D) Cumulative probability of the amplitude of mEPSC events recorded in hypocretin/orexin neurons from control (1,518 events) and SD mice (1,557 events). ( $E$ and $\mathbf{F}$ ) Relative contributions of AMPARs and NMDARs on evoked EPSCs recorded in hypocretin/orexin neurons from control and SD mice. (E) Sample traces of evoked EPSCs carried by AMPARs and NMDARs recorded in hypocretin/orexin neurons from control (left) and SD mice (right). (F) Pooled data of the AMPAR/NMDAR ratio recorded from all hypocretin/orexin neurons from control $(n=7)$ and SD mice $(n=7)$ are presented. ${ }^{*} P<0.05$, Student's $t$ test.
We then tested the effect of a single episode of prolonged wakefulness during the normal sleep period on glutamatergic synaptic transmission in hypocretin/orexin neurons, since these neurons are thought to be the target of modafinil treatment (34). Miniature excitatory postsynaptic currents (mEPSCs) were recorded in hypocretin/orexin neurons (identified by the expression of GFP under the control of a selective hypocretin/orexin promoter) in brain slices taken from mice sacrificed 0,1 or 2 hours after administration of modafinil or saline.

Changes in the frequency of mEPSCs are thought to result from modification of the presynaptic component of synaptic transmission, while changes in the amplitude of mEPSCs indicate alterations in the postsynaptic component $(25,35)$. The frequency of mEPSCs recorded immediately after the application of modafinil was $5.67 \pm 0.78 \mathrm{~Hz}(n=10)$, which was comparable to that recorded in slices from saline-treated mice $(5.72 \pm 0.69 \mathrm{~Hz} ; n=10 ; P>0.05$, Student's $t$ test). In contrast, the frequency of mEPSCs in hypocretin/orexin neurons recorded 1 hour after modafinil treatment was $9.08 \pm 1.56 \mathrm{~Hz}(n=17)$, while it was $5.54 \pm 0.70 \mathrm{~Hz}(n=17)$ in control mice $(P<0.05$, Student's $t$ test). The frequency of mEPSCs 2 hours after treatment was $7.84 \pm 0.72 \mathrm{~Hz}(n=29)$ and $5.91 \pm 0.58 \mathrm{~Hz}$ $(n=29)$ in slices from modafinil- and saline-treated mice, respectively $(P<0.05$, Student's $t$ test) (Figure $1, \mathrm{~B}$ and $\mathrm{C}$ ).

The cumulative probability curves for the amplitude of mEPSC events recorded 0,1 and 2 hours after treatment in slices from control and modafinil-treated mice were plotted (Figure 1, D-F). The amplitude of mEPSCs was significantly increased 1 and 2 hours after modafinil treatment $(P<0.01$, Kolmogorov-Smirnov test; Figure 1, E and F), whereas there was no significant difference between saline- and modafinil-treated mice immediately after modafinil administration (Figure 1D).

The ratio of synaptic currents carried by $\alpha$-amino-3-hydroxy-5methylisoxazole-4-propionic acid (AMPA) glutamate receptors to those carried by NMDA glutamate receptors (AMPAR/NMDAR ratio) increases persistently during $\operatorname{LTP}(25,36,37)$. We measured the relative contributions of AMPAR and NMDAR to evoked excitatory postsynaptic currents (EPSCs) in hypocretin/orexin neurons in slices from control and modafinil-treated mice 1 hour after administration of modafinil or saline. Evoked EPSCs were recorded under voltage clamp at $+40 \mathrm{mV}$ in the absence and then presence of the selective NMDAR antagonist DL-2-amino-5-phosphonovaleric acid (AP5) as has been described (25). As shown in Figure 1, G and H, the AMPAR/NMDAR ratio recorded in hypocretin/orexin neurons in slices from mice acutely exposed to modafinil was increased compared with neurons from saline-treated mice (modafinil: $3.50 \pm 0.23$, $n=10$; saline: $2.63 \pm 0.29, n=10 ; P<0.05$, Student's $t$ test).

These data suggest that prolonged wakefulness resulting from acute modafinil treatment induces LTP at excitatory synapses on hypocretin/orexin neurons, since application of modafinil directly to hypothalamic slices from normal mice does not induce any change 

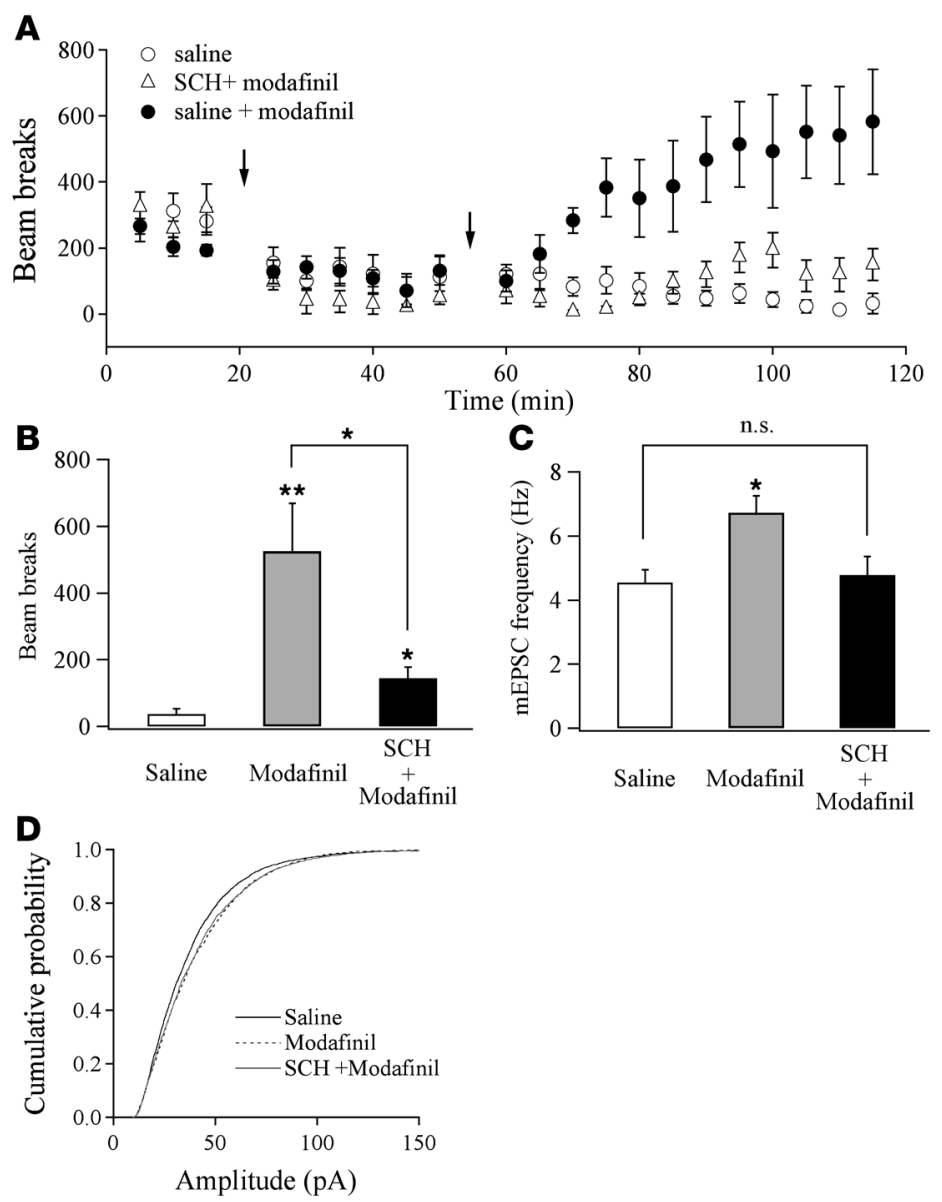

Figure 4

Blockade of D1 receptor-mediated pathways attenuates modafinil-induced effects on wakefulness and synaptic plasticity. (A) Time course of locomotor activity shows that pretreatment of a selective D1 receptor antagonist $\mathrm{SCH} 23390$ (SCH) attenuates modafinil effects on locomotor activity. Each point represents averaged beam breaks within a block of 5 minutes detected from all animals in each group. The first arrow indicates the injection of $\mathrm{SCH}$ 23390 or saline. The second arrow indicates the injection of modafinil or saline. (B) Mean beam breaks per 5 minutes of the last 30-minute session of our experiment monitored from all 3 groups. ${ }^{*} P<0.05$; ${ }^{* *} P<0.01$. (C) The mean frequency of $m E P S C s$ recorded in hypocretin/orexin neurons from all 3 groups. ${ }^{*} P<0.05$, ANOVA; NS: $P>0.05$. (D) Cumulative probability of the amplitude of mEPSCs recorded in hypocretin/orexin neurons from mice treated with saline (2,829 events), modafinil (3,140 events), and $\mathrm{SCH} 23390$ plus modafinil $(2,725$ events).

in the activity of hypocretin/orexin neurons (data not shown). Moreover, mEPSCs were also monitored in non-hypocretin/orexin neurons in the LH area after the acute application of modafinil. Both the frequency $(2.82 \pm 0.73 \mathrm{~Hz} ; n=12)$ and amplitude $(23.35 \pm 3.25 \mathrm{pA})$ of mEPSCs in modafinil-treated mice were comparable to those in saline-treated mice $(2.58 \pm 0.59 \mathrm{~Hz}, 24.49 \pm 1.68 \mathrm{pA} ; n=12 ; P>0.05)$ 1 hour after the application of modafinil (or saline), with no significant difference between the groups $(P>0.05$, Student's $t$ test). These results demonstrate that the effect of modafinil on synaptic plasticity is specific to hypocretin/orexin neurons.

The induction of LTP at glutamatergic synapses on hypocretin/ orexin neurons following an acute modafinil-mediated increment in wakefulness led us to hypothesize that experience-dependent synaptic plasticity would also develop in hypocretin/orexin neurons after chronic exposure to modafinil-induced prolonged wakefulness. Male C57BL/6 mice were habituated to locomotor testing cages once daily for 3 days. Following habituation, modafinil $(20 \mathrm{mg} / \mathrm{kg} ; n=8)$ or saline $(n=8)$ was administered once daily for 7 days, and locomotor activity (indicating wakefulness during the light portion of the cycle) was measured. The minimal effective dose in mice reported in previous studies was used to avoid a ceiling effect in this experiment (30). Mice showed increased locomotor activity upon the first exposure to modafinil (main effect of day $\left.\left[F_{1,9}=2.242 ; P<0.05\right]\right)$ and the increment lasted as long as 2 hours (data not shown). Repeated modafinil administration resulted in a sensitization of the locomotor response with a main effect of treatment $\left(F_{1,11}=15.049 ; P<0.01\right)$ and a day-by-treatment interaction $\left(F_{1,9}=2.262 ; P<0.01\right)$. Modafinil-treated mice showed significantly elevated locomotor activity on day 10 compared with the response to modafinil on day 4 (the first treatment; 1-way repeated ANOVA, $P<0.05$ ). These data suggest that neuronal plasticity takes place in circuitry mediating modafinil-induced wakefulness (Figure 2A).

One day after completion of the 7-day treatment with modafinil or saline, the frequency of mEPSCs recorded in hypocretin/orexin neurons in slices was significantly greater $(P<0.05$, Student's $t$ test; Figure 2, B and C) in slices from modafinil-treated mice $(9.49 \pm 1.35 \mathrm{~Hz} ; n=15)$ than in slices from control mice $(6.24 \pm 0.66 \mathrm{~Hz} ; n=18)$. In addition, the amplitude of mEPSC events was greater in neurons from modafinil-treated mice $(50.7 \pm 3.72 \mathrm{pA} ; n=15)$ than in neurons from control mice $(37.4 \pm 1.85 \mathrm{pA} ; n=18$; Figure $2 \mathrm{D})$; the cumulative probability of mEPSC amplitude obtained from modafinil-treated compared with control mice was significantly shifted to the right $(P<0.001$, KolmogorovSmirnov test; Figure 2E). Finally, the AMPAR/NMDAR ratio of evoked EPSCs was modestly (not significantly) increased in neurons from modafinil-treated mice $(3.92 \pm 0.40 ; n=14)$ compared with neurons from saline-treated mice $(3.15 \pm 0.26$; $n=14)(P>0.05$, Student's $t$ test $)$.

We next confirmed that anatomical changes consistent with synaptic plasticity occurred following repeated modafinil administration by measuring the number of asymmetric synapses on hypocretin/orexin-containing cell bodies using a previously reported method $(22,38)$. Unbiased ultrastructural analysis revealed a significant elevation in the number of asymmetric synapses on hypocretin/orexin perikarya in modafiniltreated mice (saline: $17.58 \pm 1.97$ boutons per $100-\mu \mathrm{m}$ membrane length, $n=10$; modafinil: $26.84 \pm 2.85$ boutons per $100-\mu \mathrm{m}$ membrane length, $n=10 ; P<0.05$; Figure 2, F and G).

To confirm that prolonged wakefulness induces experiencedependent plasticity in hypocretin/orexin neurons, we examined the synaptic strength of glutamatergic synapses on hypocretin/ orexin neurons following an episode of SD. Hypocretin-GFP mice were deprived of sleep for 4 hours by gentle handling as reported previously (9). Immediately after completion of the 4-hour SD, the frequency of mEPSCs recorded in hypocretin/orexin neurons was significantly increased $(P<0.05$, Student's $t$ test; Figure $3 \mathrm{~B})$ in SD mice $(9.75 \pm 0.57 \mathrm{~Hz} ; n=28)$ as compared with control mice $(6.34 \pm 0.57 \mathrm{~Hz} ; n=28)$. In addition, the amplitude of mEPSCs was greater $(P<0.05$, Student's $t$ test; Figure $3 \mathrm{C})$ in neurons from SD 
A

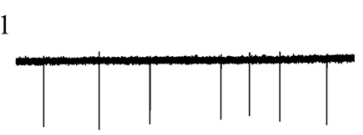

2
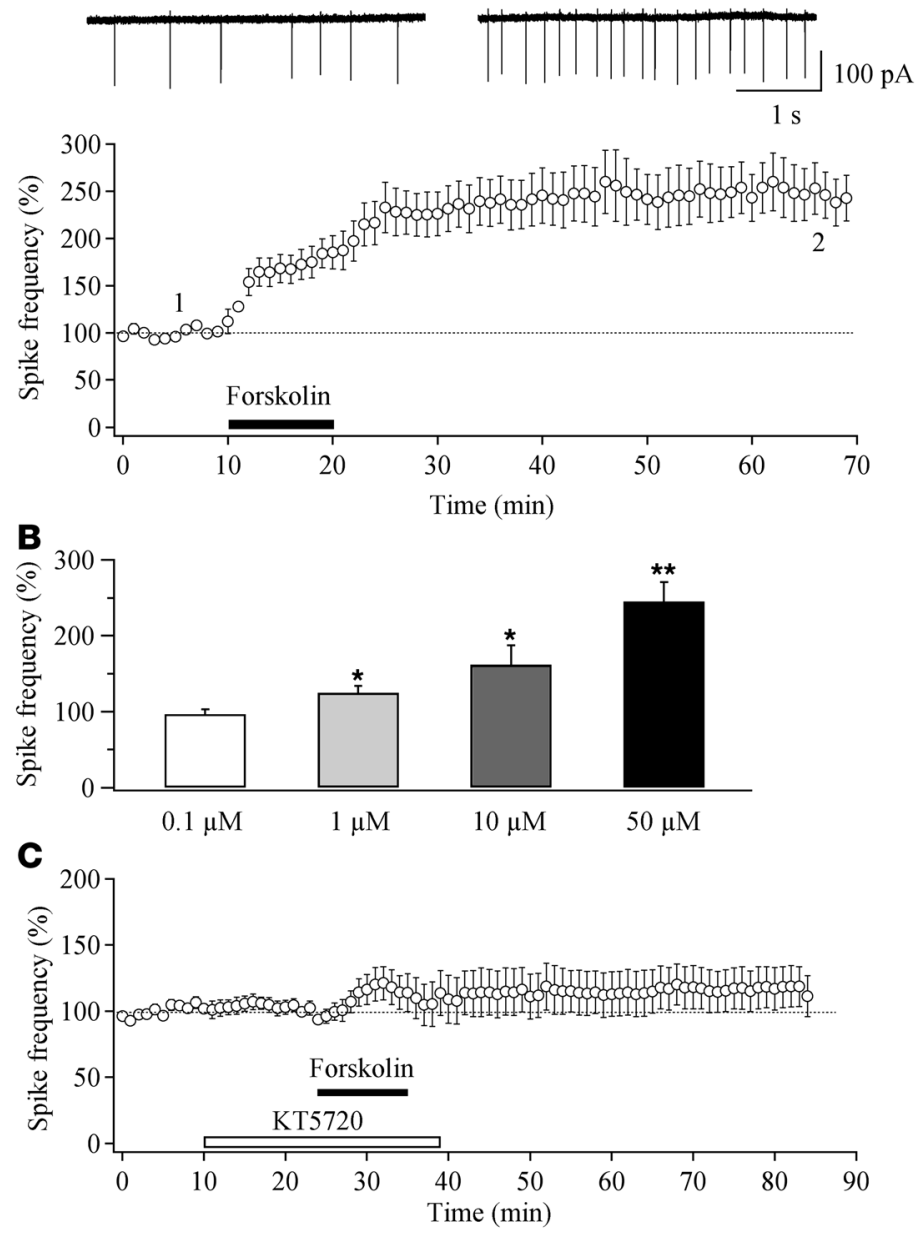

Figure 5

Forskolin induces a long-lasting potentiation of spike generation in hypocretin/orexin neurons. (A) Time course of For-LTP of action potentials in hypocretin/orexin neurons. Representative traces of spikes (action currents) recorded extracellularly before and 1 hour after the application of forskolin were taken at the times indicated on the graph. The black bar indicates the application of forskolin. (B) Bar graph indicates the dose-dependence of For-LTP in hypocretin/orexin neurons. Percentage changes in spike frequency recorded 30 minutes after the withdrawal of forskolin at 4 different doses are shown. ${ }^{\star} P<0.05 ;{ }^{* \star} P<0.01$. (C) Time course of spike frequency indicates that inhibition of PKA eliminates For-LTP of action potentials in hypocretin/orexin neurons ( $P>0.05$, paired Student's $t$ test).

mice $(28.32 \pm 1.61 \mathrm{pA} ; n=28)$ than in neurons from control mice $(23.64 \pm 1.52 \mathrm{pA} ; n=28)$; the cumulative probability of mEPSC amplitude obtained from SD mice was significantly shifted to the right compared with control mice $(P<0.001$, KolmogorovSmirnov test; Figure 3D). Finally, the AMPAR/NMDAR ratio of evoked EPSCs was significantly increased in neurons from SD mice $(3.61 \pm 0.58 ; n=7)$ compared with neurons from control mice $(2.2 \pm 0.23 ; n=7)(P<0.05$, Student's $t$ test; Figure $3, \mathrm{E}$ and $\mathrm{F})$.

It has been suggested that the DA system is involved in modafinilinduced wakefulness $(29,31)$ and that D1 receptors are necessary for stimulation of hypocretin/orexin neurons in the LH $(39,40)$. Systemic application of the selective D1 receptor antagonist $\mathrm{SCH}$ $23390[\mathrm{R}(+)$-7-chloro-8-hydroxy-3-methyl-1-phenyl-2,3,4,5-tetrahydro-1H-3-benzazepine hydrochloride] blocks the D1 recep- tor-mediated effect of cocaine on synaptic strength in DA neurons (41). As shown in Figure 4, A and B, pretreatment with SCH $23390(0.5 \mathrm{mg} / \mathrm{kg}) 30$ minutes before the application of modafinil $(100 \mathrm{mg} / \mathrm{kg})$ significantly attenuated the ability of modafinil to stimulate locomotor activity $(P<0.05$; saline: $37.1 \pm 16.6, n=6$; modafinil: $525.3 \pm 143.5, n=5$; $\mathrm{SCH}$ 23390 plus modafinil: $145.0 \pm 32.5, n=5$; Figure $4 B$ ). In addition, the frequency of mEPSCs in hypocretin/orexin neurons recorded 1 hour after modafinil treatment was significantly potentiated in mice treated with modafinil only (control mice: $4.55 \pm 0.38 \mathrm{~Hz}, n=15$; modafinil: $6.59 \pm 0.53 \mathrm{~Hz}, n=16$ ) but not in mice treated with SCH 23390 plus modafinil $(4.85 \pm 0.58 \mathrm{~Hz} ; n=14 ; P<0.05$, ANOVA; Figure 4C). In contrast, the cumulative probability of mEPSC amplitude obtained from mice treated with SCH 23390 plus modafinil compared with control mice was significantly shifted to the right $(P<0.001$, Kolmogorov-Smirnov test; Figure 4D, solid gray line), just as in mice treated with modafinil alone $(P<0.001$, Kolmogorov-Smirnov test; Figure 4D, dotted line). Thus, pretreatment with the D1 receptor antagonist attenuated modafinil-induced prolonged wakefulness, and this may have been due to the depression of potentiation of mEPSC frequency in hypocretin/orexin neurons.

Activity-dependent synaptic plasticity occurs in bypocretin/orexin neurons. We tested the ability of forskolin to induce LTP in hypocretin/orexin neurons to determine the mechanisms underlying the synaptic potentiation resulting from prolonged wakefulness. Bath application of forskolin, an activator of adenylyl cyclase, induces LTP at all synapses on neurons in the hippocampus (42-45). The forskolin-induced LTP (For-LTP) is PKA dependent, and the PKA cascade is right downstream to the activation of the D1 dopamine receptor $(39,43,44)$. Bath application of forskolin for 10 minutes induced a long-lasting potentiation of spike firing in hypocretin/orexin neurons (Figure 5). This potentiation persisted for the duration of the experiment (more than 1 hour; $n=5$; Figure 5A). For-LTP is dose dependent and can be observed at a concentration as low as $1 \mu \mathrm{M}$ (Figure $5 \mathrm{~B}$ ). In slices pretreated with a membrane-permeable PKA inhibitor, KT5720 (20 $\mu \mathrm{M})$, For-LTP of spike frequency was largely blocked $(116.7 \% \pm 15.4 \%$ of baseline; $n=7 ; P>0.05$; Figure 5C).

Forskolin $(50 \mu \mathrm{M})$ also induced LTP of mEPSC frequency in hypocretin/orexin neurons $(196.7 \% \pm 11.5 \%$ of baseline 30 minutes after washout of forskolin; $n=5 ; P<0.01$, paired Student's $t$ test; Figure 6, A and B). The mean amplitude of mEPSCs was also significantly potentiated by forskolin $(125.2 \% \pm 11.5 \%$ of baseline; $n=5 ; P<0.01$, paired Student's $t$ test; Figure 6C), without significant changes in rise time, decay time, or half-width of events (data not shown). There was also a rightward shift in the cumulative distribution of mEPSC amplitude 30 minutes after removal of forskolin (Kolmogorov-Smirnov test, $P<0.001$; Figure 6C, right), suggesting that elevating cAMP levels results in LTP of glutamatergic synaptic transmission in hypocretin/orexin neurons at both pre- and postsynaptic sites.

To confirm that cAMP acts postsynaptically in hypocretin/orexin neurons to induce For-LTP, we included $\mathrm{PKI}_{6-22}$, a membraneimpermeable and highly specific inhibitory peptide that binds to the catalytic subunit of PKA, in the patch pipette. In these experiments, we allowed 25-30 minutes for infusion of $\mathrm{PKI}_{6-22}(40 \mu \mathrm{M})$ into hypocretin/orexin cells before application of forskolin. In the 
$\mathbf{A}$
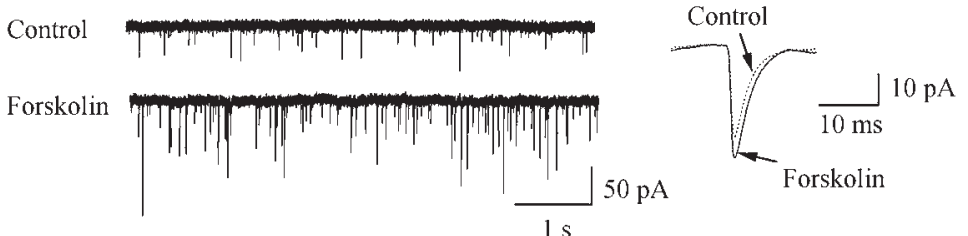

B
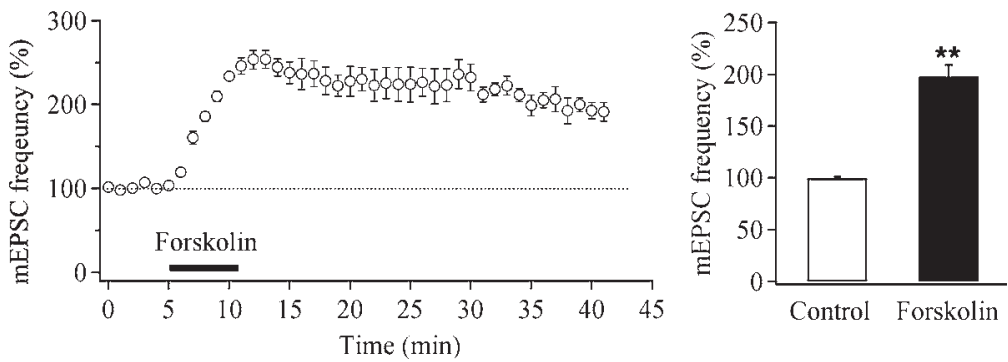

C

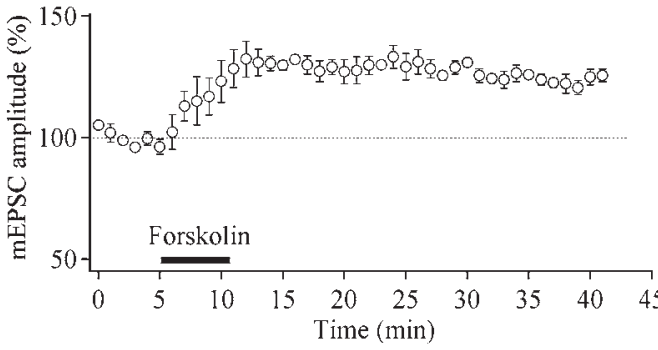

D

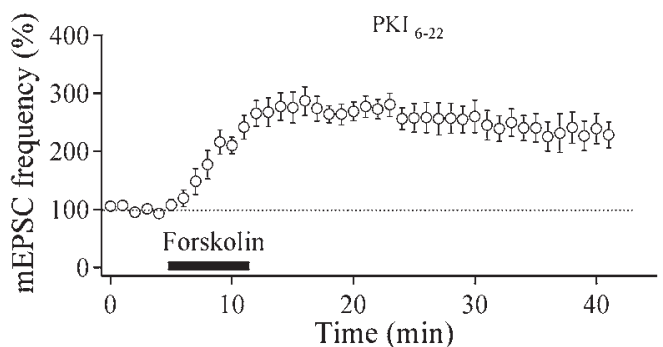

E
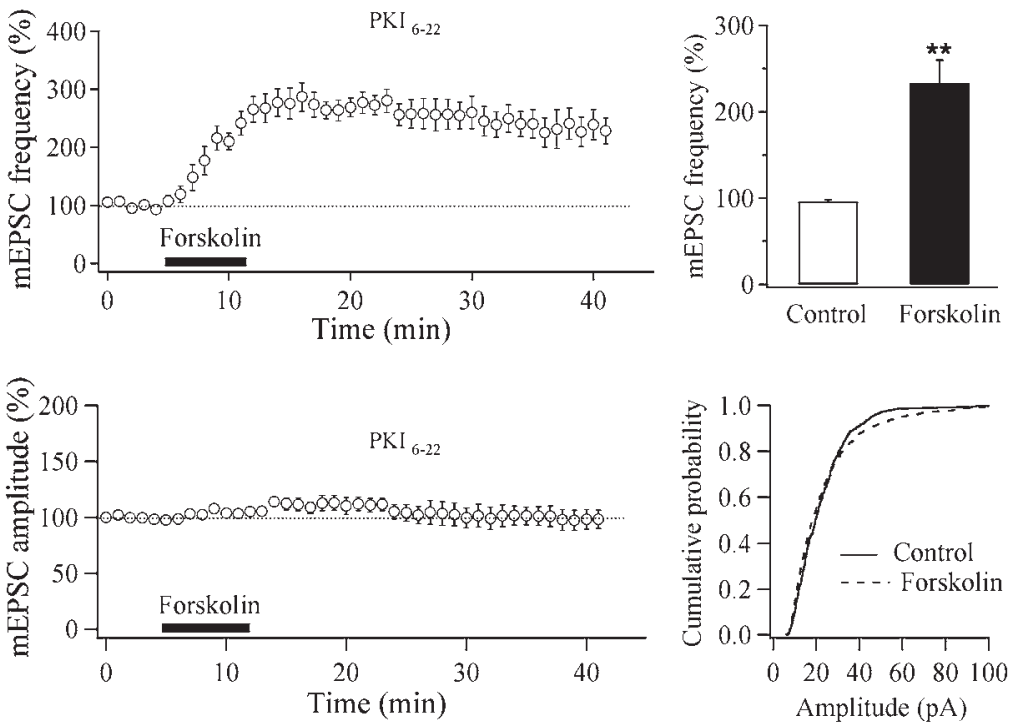

Figure 6

LTP of glutamatergic synapses on hypocretin/orexin neurons elicited by application of forskolin. (A) Sample traces (left) and single events (right) of mEPSCs recorded in hypocretin/orexin neurons before and 30 minutes after the application of forskolin. (B) Time course of the averaged frequency of mEPSCs from all tested neurons is shown on the left, and pooled data of the frequency of mEPSCs from all neurons before and 30 minutes after the application of forskolin are shown on the right. ${ }^{* \star} P<0.01$. (C) Time course of the averaged amplitude of mEPSCs recorded in our experiments is shown on the left. Right: Cumulative probability of mEPSC amplitude recorded before (831 events) and 30 minutes after the application of forskolin $(1,566$ events) $(P<0.001$, KolmogorovSmirnov test). (D) LTP of the frequency of mEPSCs induced by forskolin is intact in the presence of $\mathrm{PKI}_{6-22}$ in the pipette solution. Left: Time course of mEPSC frequency during the postsynaptic application of $\mathrm{PKI}_{6-22}$. Right: Pooled data of $\mathrm{mEPSC}$ frequency from all tested neurons before and 30 minutes after the application of forskolin. ${ }^{* *} P<0.01$, paired Student's $t$ test. (E) LTP of mEPSC amplitude is blocked when $\mathrm{PKI}_{6-22}$ is present in pipette solution. Left: Time course of mEPSC amplitude recorded in our experiments during the postsynaptic application of $\mathrm{PKI}_{6-22}$. Right: Cumulative probability of mEPSC amplitude recorded before (469 events) and $30 \mathrm{~min}-$ utes after the application of forskolin (1,100 events) when $\mathrm{PKI}_{6-22}$ was applied to postsynaptic neurons ( $P>0.05$, Kolmogorov-Smirnov test). presence of $\mathrm{PKI}_{6-22}$, forskolin did not alter the mean amplitude of mEPSCs (Figure 6E; $98.57 \% \pm 8.83 \%$ of baseline; $n=5 ; P>0.05$; 30 minutes after removal of forskolin), and the cumulative probability of the mEPSC amplitude showed little change $(P>0.05$, Kolmogorov-Smirnov test; Figure 6E, right). In contrast, the frequency of mEPSCs was still significantly potentiated by forskolin 30 minutes after the removal of drug $(233.3 \% \pm 26.25 \%$ of baseline; $P<0.01$; Figure 6D).

For-LTP is occluded in bypocretin/orexin neuronsin modafinil-treated mice. If in vivo modafinil treatment induces PKA-dependent synaptic plasticity, we would expect that induction of For-LTP in slices from modafinil-treated mice should be occluded. Hypothalamic slices were prepared 2 hours after acute administration of modafinil or saline. Forskolin $(50 \mu \mathrm{M})$ induced a comparable increment in mEPSC frequency in modafinil-treated mice $(194.95 \% \pm 12.83 \%$ of baseline; $n=6$ ) compared with that in saline-treated mice $(208.9 \% \pm 9.25 \%$ of baseline; $n=6 ; P>0.05$, Student's $t$ test; Figure $7 \mathrm{~A})$. Similarly, mEPSC amplitude was increased in both groups of mice (Kolmogorov-Smirnov test; Figure 7, C and D). However, the potentiation of amplitude of mEPSCs was significantly smaller in mice acutely exposed to modafinil $(109.94 \% \pm 4.08 \% ; n=6)$ than in control mice $(123.18 \% \pm 2.67 \% ; n=6 ; P<0.05$, Student's $t$ test; Figure $7 \mathrm{~B})$. In order to eliminate the possibility of a ceiling effect, we also tested a lower forskolin concentration $(5 \mu \mathrm{M})$. The frequency of 


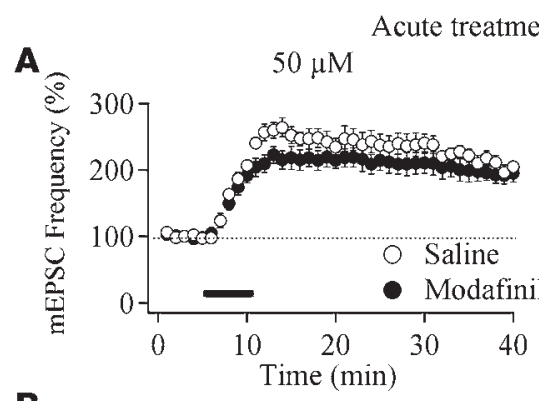

B

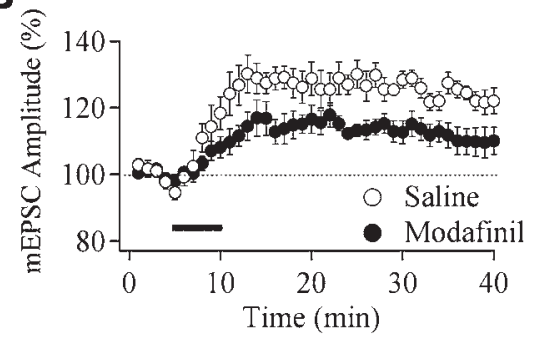

C

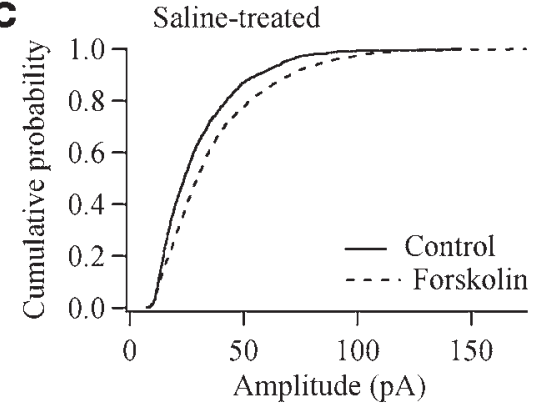

D

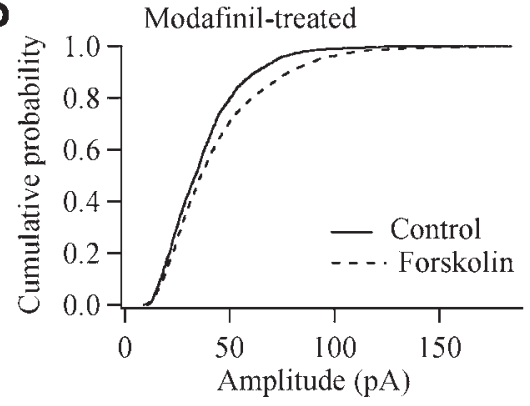

E

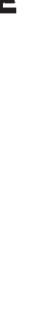

$\mathbf{F}$
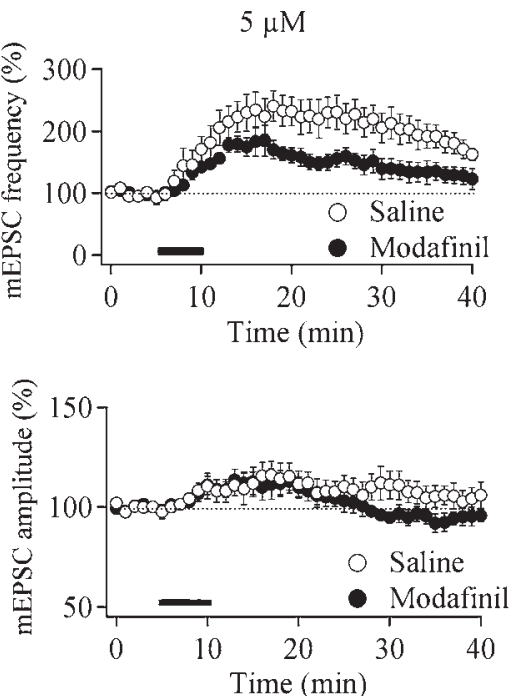

G

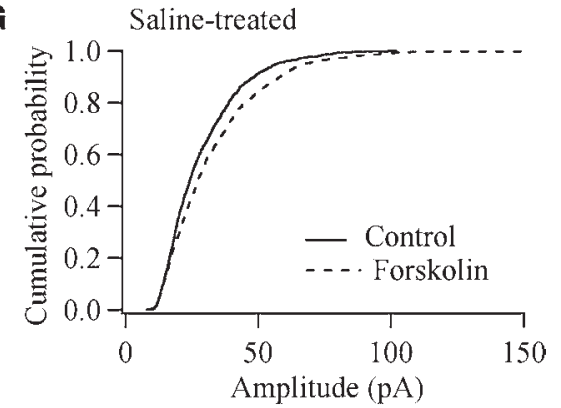

H

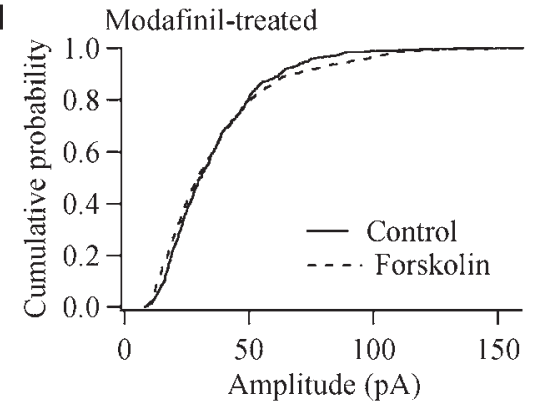

\section{Figure 7}

Occlusion of For-LTP in hypocretin/orexin neurons in mice exposed to prolonged wakefulness. (A) Time courses indicate that ForLTP of mEPSC frequency existed in control and modafinil-treated mice. (B) Time courses indicate that For-LTP of mEPSC amplitude is significantly attenuated in modafinil-treated mice compared with control mice $(P<0.05$, Student's $t$ test). (C and D) Cumulative probability of mEPSC amplitude detected before and 30 minutes after the treatment of forskolin in control (C) and modafinil-treated mice (D) confirms a significant enhancement after the treatment of forskolin $(P<0.001$, Kolmogorov-Smirnov test). (C) Control, 1,101 events; forskolin treatment, 1,770 events. (D) Control, 1,282 events; forskolin treatment, 2,387 events. (E-H) LTP of mEPSC frequency and amplitude triggered by forskolin is occluded in mice acutely exposed to modafinil. (E) LTP of mEPSC frequency is significantly attenuated in modafinil-treated compared with control mice $(P<0.05$, Student's $t$ test). (F) LTP of mEPSC amplitude induced by forskolin $(5 \mu \mathrm{M})$ exists in control mice but not in modafiniltreated mice. ( $\mathbf{G}$ and $\mathbf{H}$ ) Cumulative probability of mEPSC amplitude detected before and 30 minutes after the treatment with forskolin in control (G) and modafinil-treated mice (H). (G) A significant potentiation induced by forskolin is confirmed $(P<0.001$, Kolmogorov-Smirnov test). Control: 1,124 events; forskolin treatment: 1,666 events. (H) No significant changes in mEPSC amplitude are detected after the treatment with forskolin $(P>0.05$, Kolmogorov-Smirnov test). Control: 516 events; forskolin treatment: 723 events.
mEPSCs recorded 30 minutes after the treatment of forskolin $(5 \mu \mathrm{M})$ was significantly attenuated in hypocretin/orexin neurons from modafinil-treated mice $(126.32 \% \pm 14.16 \%$ of baseline; $n=6$; Figure 7E) compared with those from control mice $(168.03 \% \pm 15.95 \%$ of baseline; $n=6$; Figure $7 \mathrm{E} ; P<0.05$, Student's $t$ test). The amplitude of mEPSCs returned to baseline 15 minutes after withdrawal of forskolin in modafinil-treated mice $(P>0.05$, Kolmogorov-Smirnov test; Figure 7, F and H). In contrast, mEPSC amplitude remained high in control mice for the duration of the experiment $(P<0.05$, Kolmogorov-Smirnov test; Figure $7, \mathrm{~F}$ and $G)$. These data suggest that induction of For-LTP of mEPSCs is impaired in mice previously exposed to prolonged wakefulness as a result of acute treatment with modafinil.

The frequency of mEPSCs detected 30 minutes after washout of forskolin $(50 \mu \mathrm{M})$ was significantly lower in slices from mice exposed to modafinil repeatedly $(150.1 \% \pm 16.5 \%$ of baseline; $n=5$; Figure $8 \mathrm{~A}$ ) as compared with slices from mice treated with saline $(240.8 \% \pm 31.6 \%$ of baseline; $n=6$; Figure 8 , A and B; $P<0.05$,
Student's $t$ test). The amplitude of mEPSCs remained elevated 30 minutes after withdrawal of forskolin in saline-treated mice $(120.97 \% \pm 7.87 \%$ of baseline; $n=6)$ but not in modafinil-treated mice $(98.45 \% \pm 6.96 \%$ of baseline; $n=5$; Figure $8, C$ and D). The Kolmogorov-Smirnov test of cumulative probability of mEPSC amplitude before and after forskolin treatment confirmed that forskolin significantly increased the amplitude of mEPSCs in slices from saline-treated mice $(P<0.001$; Figure $8 \mathrm{E})$ but not in slices from modafinil-treated mice $(P>0.05$; Figure $8 \mathrm{~F})$.

Taken together, these data suggest that similar mechanisms underlie modafinil-induced, experience-dependent synaptic plasticity and For-LTP.

\section{Discussion}

Prolonged wakefulness at the expense of sleep results in beneficial (such as antidepressive) and adverse (such as cognitive impairment) effects $(1,3-5,46)$; however, the fundamental neurobiological changes resulting from SD remain to be explored. Previ- 
Chronic treatment of modafinil

A
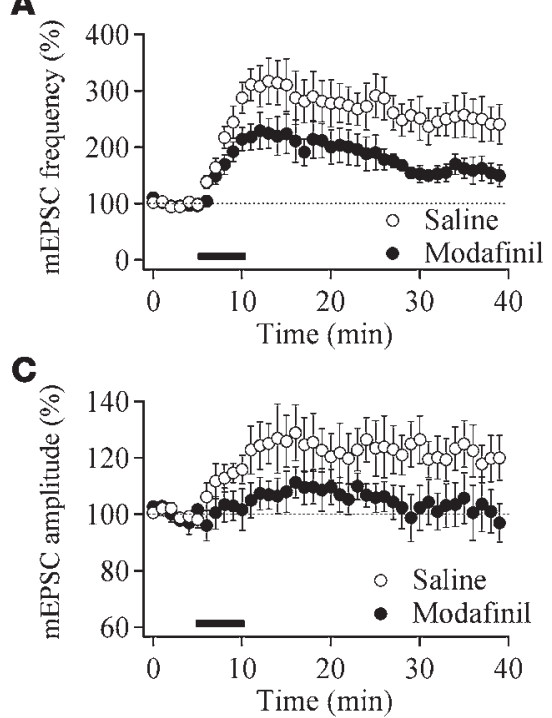

E

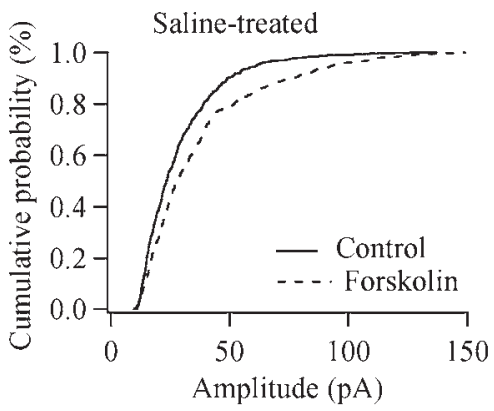

B

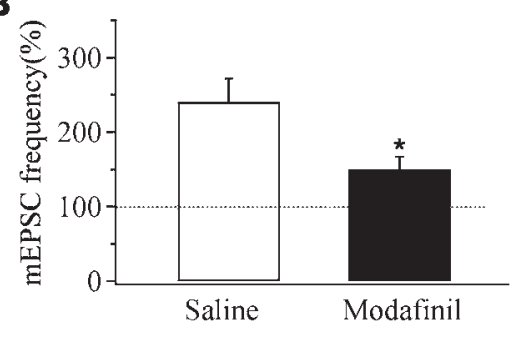

D

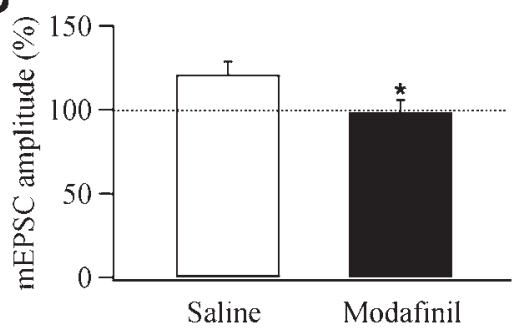

F

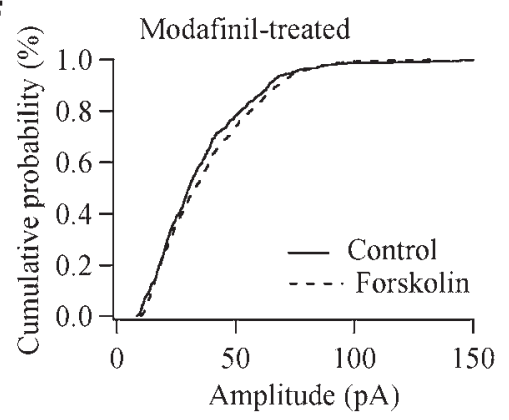

\section{Figure 8}

Occlusion of For-LTP in hypocretin/orexin neurons in mice repeatedly exposed to prolonged wakefulness. (A) LTP of mEPSC frequency is attenuated in mice chronically treated with modafinil compared with saline-treated mice. (B) Pooled data from all tested neurons recorded 30 minutes after the application of forskolin demonstrate that LTP of mEPSC frequency induced by forskolin $(50 \mu \mathrm{M})$ is significantly attenuated in mice repeatedly treated with modafinil compared with control mice. ${ }^{*} P<0.05$. (C) Time course shows that LTP of mEPSC amplitude exists in control mice but not in modafinil-treated mice. (D) Pooled data from all tested neurons recorded 30 minutes after the application of forskolin demonstrate that LTP of mEPSC amplitude is blocked in mice repeatedly treated with modafinil. ${ }^{*} P<0.05$, Student's $t$ test. (E) Cumulative probability of mEPSC amplitude detected before (476 events) and 30 minutes after the treatment of forskolin (793 events) in control mice confirms a significant enhancement after the treatment $(P<0.001$, Kolmogorov-Smirnov test). (F) Cumulative probability of mEPSC amplitude detected before (527 events) and 30 minutes after the treatment of forskolin $(1,296$ events) in modafinil-treated mice confirms that there was no significant change in the amplitude of mEPSC after the treatment with forskolin $(P>0.05$, Kolmogorov-Smirnov test). ous reports have suggested that hypocretin/orexin neurons are activated following modafinil treatment and SD $(9,34)$, but the mechanisms underlying adaptive changes in the activity of hypocretin/orexin neurons have not been examined. In this study we induced prolonged wakefulness in mice either by administering modafinil or by gently handling animals during the light phase, when mice are normally asleep. Previous data from rats and Syrian hamsters showed that in vivo administration of modafinil during the light phase prolonged wakefulness and reduced slow wave and paradoxical sleep $(32,33)$. Using modafinil could reduce the stress resulting from experimental manipulations leading to sleep loss. The results of this study provide the first evidence to our knowledge that experience-dependent synaptic plasticity takes place at glutamatergic synapses on hypocretin/orexin neurons during prolonged wakefulness. LTP at inputs to hypocretin/orexin neurons provides a mechanism for how wake-promoting centers maintain prolonged wakefulness during sleep loss.

A single administration of modafinil leads to an LTP-like potentiation of synaptic strength pre- and postsynaptically, which lasts for the duration of wakefulness (Figure 1). Chronic administration of modafinil induced synaptic plasticity in hypocretin/orexin neurons, as measured by increased synaptic strength and increased number of synapses on hypocretin/orexin-containing perikarya (Figure 2), suggesting that prolonged wakefulness over several days leads to reorganization of excitatory synapses on hypocretin/orexin neurons. This type of synaptic reorganization has also been observed following food deprivation (22). Consistent with these adaptive changes induced by modafinil treatment, a single episode of SD led to a similar potentiation of synaptic strength at glutamatergic synapses on hypocretin/orexin neurons in this study (Figure 3), suggesting that experience-dependent synaptic plasticity in hypocretin/orexin neurons may underlie prolonged wakefulness induced by physiological and environmental factors.

It has already been shown that modafinil enhances the DA tone in the brain and that the DA system regulates (enhances in most cases) the activity of hypocretin/orexin neurons $(31,39,40)$. Our experiments with a selective D1 receptor antagonist, SCH 23390, suggest that D1 receptor activation contributes to expression of the experience-dependent synaptic plasticity observed in this study. Pretreatment with SCH 23390 significantly attenuated modafinilinduced prolonged wakefulness and depressed the presynaptic potentiation of glutamatergic synapses on hypocretin/orexin neurons (Figure 4). There has been ample evidence that SD is associated with an increased DA tone in the brain $(46,47)$. Therefore, enhanced activity of the DA system during prolonged wakefulness resulting from SD may also lead to experience-dependent synaptic plasticity in hypocretin/orexin neurons reported here.

It is suggested in this study that LTP can be elicited following intensive activation of neuronal ensembles centered on hypocretin/orexin neurons (Figure 6). Occlusion of LTP has been observed following regimens that might be expected to result in experiencedependent synaptic plasticity, such as training in a novel task or administration of drugs of abuse $(24,25)$. The occlusion of ForLTP in hypocretin/orexin neurons by modafinil treatment indi- 
cates that the molecular and cellular machinery responsible for LTP (in particular the PKA-dependent pathways downstream to D1 receptor activation) contribute to experience-dependent synaptic plasticity following prolonged wakefulness (Figures 7 and 8). It is noteworthy that the attenuation of For-LTP was greater in slices from animals treated chronically with modafinil than in slices from animals treated acutely (Figures 7 and 8), indicating that full expression of LTP was established only after chronic treatment. These results are consistent with the behavioral experiments, which showed that locomotor activity was enhanced by acute modafinil administration but continued to increase over several days of administration (Figure 2A). For-LTP was not completely occluded in slices from modafinil-treated mice, perhaps because synaptic plasticity resulting from wakefulness due to exposure to modafinil only occurs at a subset of synapses, whereas For-LTP occurs at all synapses on hypocretin/orexin neurons.

Our data further suggest the involvement of signaling pathways mediated through other neurotransmitters in experience-dependent plasticity reported in this study. Blockade of D1 receptor activation did not completely abolish modafinil-induced prolonged wakefulness (Figure 4). The potentiation of the postsynaptic component of glutamatergic synapses still existed after the modafinil treatment in the presence of the D1 receptor blockade. These results are consistent with the involvement of norepinephrine- and histamine-mediated pathways in modafinil-induced effects $(34,48)$. In addition, it is also worth investigating whether the lack of complete occlusion of For-LTP in mice exposed to prolonged wakefulness was due to the involvement of other signaling pathways. There has been a report of a more robust effect of modafinil in hypocretin/orexin-KO mice (49). We believe that this might be due to the compensatory effect of other wakefulness-promoting systems in the brain in the absence of the hypocretin/orexin system. Modafinil may work with the remaining wakefulness-promoting systems in hypocretin/orexin-KO mice to exert its function. These systems may participate in modafinilinduced plasticity in hypocretin/orexin neurons.

The potentiation of excitatory inputs to hypocretin/orexin neurons reported here would have a substantial impact on neuronal activity in the LH and ultimately on a wide range of behaviors related to prolonged wakefulness. In particular, this potentiation may represent the neural basis for synaptic homeostasis occurring during prolonged wakefulness. Since wakefulness-promoting centers other than the hypocretin/orexin system are also likely to be activated during prolonged wakefulness, it is reasonable to propose that experience-dependent synaptic plasticity similar to what we observed here may develop in other brain areas as well.

It has recently been hypothesized that there are cycles of potentiation and depression of excitatory synapses of cortical neurons during the daily sleep-wake cycle, through which neural functions could be reset and memory could be consolidated (2). This intriguing theory of the function of sleep in synaptic homeostasis is supported by cycles of expression of various genes (many of which play important roles in the regulation of synaptic transmission) across the sleep-wake cycle in rats $(8,50)$ and the elevated phosphorylation level of GluR1 in sleep-deprived rats (51). In the current study, we provide direct evidence to support the notion that the strength of excitatory synapses may change depending on the level of activity of neuronal ensembles participating in sleep-wake regulation (2).

While sleep regulates synaptic activity in brain regions such as the cortex (2), adaptive changes in synaptic strength (experiencedependent synaptic plasticity) may also contribute to the main- tenance of the behavioral state. This may be particularly important for neuronal systems necessary for homeostatic mechanisms involved in arousal, such as hypocretin/orexin neurons and other wakefulness-promoting centers.

In summary, from an evolutionary point of view, the experiencedependent potentiation of excitatory synapses on hypocretin/ orexin neurons during prolonged wakefulness would be adaptive, since the hypocretin/orexin system is critical for positive energy balance (52), which is required to maintain a sufficient energy supply for animals to interact with the environment. It is therefore intriguing to hypothesize that repeated, prolonged wakefulness resulting from sleep restriction (deprivation) could lead to significant adverse effects (such as unbalanced energy consumption) as a result of experience-dependent synaptic plasticity in brain areas involved in both arousal and energy balance.

\section{Methods}

All animal procedures were performed in accordance with NIH Guide for the Care and Use of Laboratory Animals and were approved by the Yale University Animal Care and Use Committee.

Modafinil treatment and locomotor activity. Locomotor activity was measured as previously described (53). Male C57BL/6 mice (6-8 weeks old; Jackson Laboratory) were group housed and maintained on a 12-hour light/ 12-hour dark cycle (lights on at 7:00 am), with food and water available ad libitum. All modafinil injections and behavioral tests were performed between 10 am and 5 pm. Modafinil (Sigma-Aldrich) was dissolved in 1\% DMSO in sterile water. All animals were habituated to the locomotor apparatus for 3 days. This was followed by a single modafinil (acute treatment, $100 \mathrm{mg} / \mathrm{kg}$, i.p.) or saline injection or 7 days of modafinil (chronic treatment, $20 \mathrm{mg} / \mathrm{kg}$, i.p.) or saline administration. On each test day, animals were habituated to the testing room for 30 minutes before being put into locomotor activity cages and were further habituated to the test boxes for 15 minutes; after habituation, animals received either a modafinil or a saline injection, and locomotor activity was monitored for 2 hours (acute administration) or 30 minutes (chronic exposures). To test the involvement of the D1 receptor in modafinil-mediated effects, a selective D1 antagonist, SCH 23390 (Tocris Bioscience), was administered (i.p.) 30 minutes before the application of modafinil.

Locomotoractivity was measured in clear plastic cages $(46 \mathrm{~cm} \times 24 \mathrm{~cm} \times 20 \mathrm{~cm})$ between 2 rows of Opto-Max sensors (Columbus Instruments) containing 16 photocells, each $2.54 \mathrm{~cm}$ apart. Another locomotor activity apparatus (MED Associates) was used for some experiments. Locomotor activity was assessed by measuring the number of beam breaks recorded during each 5-minute block across the session.

$S D$. SD was achieved as reported previously (9). Male C57BL/6 mice ( 6 weeks old) expressing GFP exclusively in hypocretin/orexin neurons were housed individually and maintained on a 12-hour light/12-hour dark cycle, with food and water available ad libitum. Mice were divided into 2 groups (control and SD), and the experiment was performed in the home cages. Mice in the SD group were SD for 4 hours (8:00 am to 12:00 pm) by gentle touching with a small, soft paintbrush upon eye closure, while mice in the control group were allowed to undergo normal sleep and waking from 8:00 am to $12: 00 \mathrm{pm}$. All mice were habituated to the presence of the experimenter and the paintbrush for 3 days prior to the SD experiment. After the experiments, all mice were sacrificed for electrophysiological studies.

Electrophysiology. Transgenic mice expressing GFP exclusively in hypocretin neurons were used to prepare coronal hypothalamic slices in this study $(26,35)$. For electrophysiological recordings after 1 bout of modafinil treatment or SD, hypothalamic slices were prepared from mice sacrificed 0,1 , or 2 hours after administration of modafinil or saline or immediately after 
SD. For electrophysiological recordings after repeated modafinil treatment, hypothalamic slices were prepared from mice sacrificed 1 day after the completion of a 7-day treatment. The electrophysiological recordings were performed in a blinded manner after the above treatments. Male mice (14-21 days old) were anesthetized with ether and then decapitated. The brains were rapidly removed and immersed in a cold $\left(4^{\circ} \mathrm{C}\right)$, oxygenated, high-sucrose solution containing (in $\mathrm{mM}$ ): sucrose 220, $\mathrm{KCl} 2.5, \mathrm{NaH}_{2} \mathrm{PO}_{4}$ 1.23, $\mathrm{NaHCO}_{3} 26, \mathrm{CaCl}_{2} 1, \mathrm{MgCl}_{2} 6$ and glucose 10 (pH 7.3 with $\mathrm{NaOH}$ ). Coronal slices ( $300 \mu \mathrm{m}$ thick) were cut on a vibratome and maintained in a holding chamber with artificial cerebrospinal fluid (ACSF; bubbled with $5 \% \mathrm{CO}_{2}$ and $95 \% \mathrm{O}_{2}$ ) containing (in $\mathrm{mM}$ ): $\mathrm{NaCl} 124, \mathrm{KCl} 3, \mathrm{CaCl}_{2} 2, \mathrm{MgCl}_{2}$ 2, $\mathrm{NaH}_{2} \mathrm{PO}_{4} 1.23, \mathrm{NaHCO}_{3} 26$, glucose $10(\mathrm{pH} 7.4$ with $\mathrm{NaOH})$. After a 1-hour recovery period, slices were transferred to a recording chamber and were constantly perfused with $\operatorname{ACSF}\left(33^{\circ} \mathrm{C}\right)$ at a rate of $2 \mathrm{ml} / \mathrm{min}$.

Extracellular recordings were made with a glass electrode filled with ACSF (resistance $\approx 2 \mathrm{M} \Omega$ ) with a multiclamp $700 \mathrm{~A}$ amplifier (Axon Instruments). A loose seal was formed (resistance $=10-30 \mathrm{M} \Omega$ ) when the micropipette touched the surface of an identified hypocretin-GFP neuron. After a 10-minute control was recorded, drugs were applied to the recording chamber by bath application.

Whole-cell voltage-clamp recording (at $-60 \mathrm{mV}$ or $+40 \mathrm{mV}$ ) was performed using low-resistance (3-4 M $\Omega$ ) pipettes. The composition of the pipette solution was as follows (in $\mathrm{mM}$ ): K-gluconate (or Cs-gluconate) 135, $\mathrm{MgCl}_{2} 2$, HEPES 10, EGTA 1.1, Mg-ATP 2, and $\mathrm{Na}_{2}$-phosphocreatin $10, \mathrm{Na}_{2}$-GTP 0.3 , pH 7.3 with $\mathrm{KOH}$. After a gigaohm (GR) seal and wholecell access were achieved, the series resistance was partially compensated by the amplifier. Both input resistance and series resistance were monitored throughout the experiments. Only those recordings with a stable series resistance $(\leq 20 \mathrm{M} \Omega)$ and input resistance were accepted. mEPSCs were recorded under voltage clamp at $-60 \mathrm{mV}$ in the presence of tetrodotoxin (TTX; $1 \mu \mathrm{M}$; Alomone Labs Ltd.) and bicuculline (30 $\mu \mathrm{M}$; SigmaAldrich). To monitor evoked EPSCs, the stimulating electrode was placed laterally to the recorded neurons at least $125 \mu \mathrm{m}$ away. Evoked EPSCs recorded in hypocretin/orexin neurons under voltage-clamp at $+40 \mathrm{mV}$ in the presence of picrotoxin (50 $\mu \mathrm{M}$; Sigma-Aldrich) contained both AMPA and NMDA components, and AMPAR-carried EPSC was obtained by applying AP5 (50 $\mu \mathrm{M}$; Sigma-Aldrich) to the recorded neurons. Then NMDAR-carried EPSC was determined by subtracting the AMPA component from the whole EPSC recorded before the application of AP5. To induce LTP, forskolin (Tocris Bioscience) was applied to recorded neurons after a stable baseline of synaptic currents was obtained. PKA inhibitor KT5720 (Sigma-Aldrich) was applied to the recording chamber via bath application, and PKA inhibitor fragment 6-22 amide ( $\mathrm{PKI}_{6-22}$; Sigma-Aldrich) was applied in the pipette solution.

All data were sampled at 3-10 kHz and filtered at $1-3 \mathrm{kHz}$ with an Apple Macintosh computer using Axograph 4.9 (Axon Instruments). Electrophysiological data were analyzed with Axograph 4.9 and plotted with KaleidaGraph 3.6 (Synergy Software) and Igor Pro 5.04 (WaveMetrics Inc.). Action currents and miniature postsynaptic currents were detected and measured with an algorithm in Axograph 4.9 (35). The frequency and mean amplitude of $\mathrm{MEPSC}$ were normalized to baseline and expressed as mean $\pm \mathrm{SEM}$.

Ultrastructural analysis of bypocretin perikarya. The unbiased analysis of synapse density on hypocretin/orexin cell bodies was performed as described previously $(22,38)$. Briefly, the $\mathrm{LH} /$ perifornical region was dissected from each brain, and the processing of the tissue for hypocretin immunocytochemistry and electron microscopy were done as described previously $(22,54)$. Hypocretin-immunolabeled cells with an equal immunoperoxidase density were studied from each group.

The analysis of synapses was performed in a double-blind fashion (22). The synaptic counts were expressed as numbers of synapses on a membrane length unit of $100 \mu \mathrm{m}$. For statistics, $n$ represents the number of neurons analyzed for each group. For each group, the mean number of synapses was calculated from 10 hypocretin/orexin neurons. F test analyses revealed significant homogeneity of variance within groups and significant nonhomogeneity of variances between groups (e.g., control versus modafinil-treated). Thus, for the intergroup multiple statistical comparisons, the Kruskal-Wallis 1-way nonparametric ANOVA test was applied. The Mann-Whitney $U$ test was used to determine the significance of differences between groups. A level of confidence of $P<0.05$ was employed for the statistical significance.

\section{Acknowledgments}

This study is supported by NIH grants DK070723 to X.-B. Gao; DK060711, DK074386, AG022880, and NS041725 to T.L. Horvath; and AA15632 to M.R. Picciotto. We thank Alex Hanxiang Wang for technical and editorial assistance.

Received for publication May 29, 2007, and accepted in revised form September 26, 2007.

Address correspondence to: Xiao-Bing Gao, Department of OB/ GYN, Yale University School of Medicine, 333 Cedar St., New Haven, Connecticut 06520, USA. Phone: (203) 785-2340; Fax: (203) 737-1883; E-mail: xiao-bing.gao@yale.edu.
1. Siegel, J.M. 2005. Clues to the functions of mammalian sleep. Nature. 437:1264-1271.

2. Tononi, G., and Cirelli, C. 2006. Sleep function and synaptic homeostasis. Sleep Med. Rev. 10:49-62.

3. Rechtschaffen, A., Bergmann, B.M., Everson, C.A., Kushida, C.A., and Gilliland, M.A. 1989. Sleep deprivation in the rat: $\mathrm{X}$. Integration and discussion of the findings. Sleep. 12:68-87.

4. Bonnet, M.H., and Arand, D.L. 2003. Clinical effects of sleep fragmentation versus sleep deprivation. Sleep Med. Rev. 7:297-310.

5. Durmer, J.S., and Dinges, D.F. 2005. Neurocognitive consequences of sleep deprivation. Semin. Neurol. 25:117-129.

6. Aston-Jones, G., and Bloom, F. 1981. Activity of norepinephrine containing locus coeruleus neurons in behaving rats anticipates fluctuations in the sleep-waking cycle. J. Neurosci. 1:876-886.

7. Cirelli, C., Pompeiano, M., and Tononi, G. 1996. Neuronal gene expression in the waking state: a role for the locus coeruleus. Science. 274:1211-1215.

8. Cirelli, C., Gutierrez, C.M., and Tononi, G. 2004.
Extensive and divergent effects of sleep and wakefulness on brain gene expression. Neuron. 41:35-43.

9. Modirrousta, M., Mainville, L., and Jones, B.E. 2005. Orexin and $\mathrm{MCH}$ neurons express c-Fos differently after sleep deprivation vs. recovery and bear different adrenergic receptors. Eur. J. Neurosci. 21:2807-2816.

10. van Economo, C. 1931. Sleep as a problem of localization. J. Nerv. Ment. Dis. 71:249-269.

11. Lin, L., et al. 1999. The sleep disorder canine narcolepsy is caused by a mutation in the hypocretin (orexin) receptor 2 gene. Cell. 98:365-376.

12. Chemelli, R.M., et al. 1999. Narcolepsy in orexin knockout mice: moleculargenetics of sleep regulation. Cell. 98:437-451.

13. de Lecea, L., and Sutcliffe, J.G. 2005. The hypocretins and sleep. FEBS J. 272:5675-5688.

14. Yoshida, K., McCormack, S., Espana, R.A., Crocker, A., and Scammell, T.E. 2006. Afferents to the orexin neurons of the rat brain. J. Comp. Neurol. 494:845-861.

15. Fujiki, N., et al. 2001. Changes in CSF hypocre- tin-1 (orexin A) levels in rats across 24 hours and in response to food deprivation. Neuroreport. 12:993-997.

16. Yoshida, Y., et al. 2001. Fluctuation of extracellular hypocretin-1 (orexin A) levels in the rat in relation to the light-dark cycle and sleep-wake activities. Eur. J. Neurosci. 14:1075-1081.

17. Zeitzer, J.M., et al. 2003. Circadian and homeostatic regulation of hypocretin in a primate model: implications for the consolidation of wakefulness. J. Neurosci. 23:3555-3560.

18. Estabrooke, I.V., et al. 2001. Fos expression in orexin neurons varies with behavioral state. J. Neurosci. 21:1656-1662.

19. Lee, M.G., Hassani, O.K., and Jones, B.E. 2005. Discharge of identified orexin/hypocretin neurons across the sleep-waking cycle. J. Neurosci. 25:6716-6720.

20. Mileykovskiy, B.Y., Kiyashchenko, L.I., and Siegel,J.M. 2005. Behavioral correlates of activity in identified hypocretin/orexin neurons. Neuron. 46:787-798.

21. Winsky-Sommerer, R., et al. 2004. Interaction 
between the corticotropin-releasing factor system and hypocretins (orexins): a novel circuit mediating stress response. J. Neurosci. 24:11439-11448.

22. Horvath, T.L., and Gao, X.B. 2005. Input organization and plasticity of hypocretin neurons: possible clues to obesity's association with insomnia. Cell Metab. 1:279-286.

23. Malenka, R.C., and Bear, M.F. 2004. LTP and LTD: an embarrassment of riches. Neuron. 44:5-21.

24. Whitlock, J.R., Heynen, A.J., Shuler, M.G., and Bear, M.F. 2006. Learning induces long-term potentiation in the hippocampus. Science. 313:1093-1097.

25. Ungless, M.A., Whistler, J.L., Malenka, R.C., and Bonci, A. 2001. Single cocaine exposure in vivo induces long-term potentiation in dopamine neurons. Nature. 411:583-587.

26. Li, Y., Gao, X.-B., Sakurai, T., and van den Pol, A.N. 2002. Hypocretin/orexin excites hypocretin neurons via a local glutamate neuron - a potential mechanism for orchestrating the hypothalamic arousal system. Neuron. 36:1169-1181.

27. Henny, P., and Jones, B.E. 2006. Innervation of orexin/hypocretin neurons by GABAergic, glutamatergic or cholinergic basal forebrain terminals evidenced by immunostaining for presynaptic vesicular transporter and postsynaptic scaffolding proteins. J. Comp. Neurol. 499:645-661.

28. Myrick, H., Malcolm, R., Tayloy, B., and LaRowe, S. 2004. Modafinil: preclinical, clinical, and postmarketing surveillance - a review of abuse liability issues. Ann. Clin. Psychiatry. 16:101-109.

29. Ballon, J.S., and Feifel, D. 2006. A systematic review of modafinil: potential clinical uses and mechanisms of action. J. Clin. Psychiatry. 67:554-566.

30. Simon, P., Panissaud, C., and Costentin, J. 1994. The stimulant effect of modafinil on wakefulness is not associated with an increase in anxiety in mice. A comparison with dexamphetamine. Psychopharmacology (Berl.). 114:597-600.

31. Wisor, J.P., et al. 2001. Dopaminergic role in stimulant-induced wakefulness. J. Neurosci. 21:1787-1794.

32. Web, I.C., Pollock, M.S., and Mistlberger, R.E. 2006.
Modafinil [2-[(Diphenylmethyl)sulfinyl]acetamide] and circadian rhythms in Syrian hamsters: assessment of the chronobiotic potential of a novel alerting compound. J. Pharmacol. Exp. Ther. 317:882-889.

33. Edgar, D.M., and Seidel, W.F. 1997. Modafinil induces wakefulness without intensifying motor activity or subsequent rebound hypersomnolence in the rat. J. Pharmacol. Exp. Ther. 283:757-769.

34. Scammell, T.E., et al. 2000. Hypothalamic arousal regions are activated during modafinil-induced wakefulness. J. Neurosci. 20:8620-8628.

35. Liu, Z.W., and Gao, X.-B. 2007. Adenosine inhibits activity of hypocretin/orexin neurons via A1 receptor in the lateral hypothalamus: a possible sleeppromoting effect. J. Neurophysiol. 97:837-848.

36. Saal, D., Dong, Y., Bonci, A., and Malenka, R.C. 2003. Drugs of abuse and stress trigger a common synaptic adaptation in dopamine neurons. Neuron. 37:577-582.

37. Borgland, S.L., Taha, S.A., Sarti, F., Fields, H.L., and Bonci, A. 2006. Orexin A in the VTA is critical for the induction of synaptic plasticity and behavioral sensitization to cocaine. Neuron. 49:589-601.

38. Pinto, S., et al. 2004. Rapid rewiring of arcuate nucleus feeding circuits by leptin. Science. 304:110-115.

39. Alberto, C.O., Trask, R.B., Quinlan, M.E., and Hirasawa, M. 2006. Bidirectional dopaminergic modulation of excitatory synaptic transmission in orexin neurons. J. Neurosci. 26:10043-10050.

40. Bubser, M., et al. 2005. Dopaminergic regulation of orexin neurons. Eur. J. Neurosci. 21:2993-3001.

41. Dong, Y., et al. 2004. Cocaine-induced potentiation of synaptic strength in dopamine neurons: behavioral correlates in GluRA(-/-) mice. Proc. Natl. Acad. Sci.U.S. A. 101:14282-14287.

42. Frey, U., Huang, Y.Y., and Kandel, E.R. 1993. Effects of cAMP simulate a late stage of LTP in hippocampal CA1 neurons. Science. 260:1661-1664.

43. Huang, Y.Y., Li, X.C., and Kandel, E.R. 1994. cAMP contributes to mossy fiber LTP by initiating both a covalently modified early phase and macromolecular synthesis-dependent late phase. Cell. 79:69-79.
44. Weisskopf, M.G., Castillo, P.E., Zalutsky, R.A., and Nicoll, R.A. 1994. Mediation of hippocampal mossy fiber long-term potentiation by cyclic AMP. Science. 265:1878-1882.

45. Otmakhov, N., et al. 2004. Forskolin-induced LTP in the CA1 hippocampal region is NMDA receptor dependent. J. Neurophysiol. 91:1955-1962.

46. Ebert, D., and Berger, M. 1998. Neurobiological similarities in antidepressant sleep deprivation and psychostimulant use: a psychostimulant theory of antidepressant sleep deprivation. Psychopharmacology (Berl.). 140:1-10.

47. Barbato, G., et al. 2007. Increased spontaneous eye blink rate following prolonged wakefulness. Physiol. Behav. 90:151-154.

48. Madras, B.K., et al. 2006. Modafinil occupies dopamine and norepinephrine transporters in vivo and modulates the transporters and trace amine activity in vitro. J. Pharmacol. Exp. Ther. 319:561-569.

49. Willie, J.T., et al. 2005. Modafinil more effectively induces wakefulness in orexin-null mice than in wild-type littermates. Neuroscience. 130:983-995.

50. Terao, A., et al. 2006. Gene expression in the rat brain during sleep deprivation and recovery sleep: an Affymetrix GeneChip study. Neuroscience. 137:593-605.

51. Pfister-Genskow, M., Tononi, G., and Cirelli, C. 2007. Molecular evidence for synaptic potentiation during waking and synaptic downscaling during sleep. Sleep. In press.

52. Sakurai, T. 2007. The neural circuit of orexin (hypocretin): maintaining sleep and wakefulness. Nat. Rev. Neurosci. 8:171-181.

53. Rabenstein, R.L., Caldarone, B.J., and Picciotto, M.R. 2006. The nicotinic antagonist mecamylamine has antidepressant-like effects in wild-type but not beta2- or alpha7-nicotinic acetylcholine receptor subunit knockout mice. Psychopharmacology (Berl.). 189:395-401.

54. Horvath, T.L., et al. 1999. Hypocretin (orexin) activation and synaptic innervation of the locus coeruleus noradrenergic system. J. Comp. Neurol. 415:145-159. 